www.periodicos.unimontes.br/index.php/caminhosdahistoria

\title{
CIRCULARIDADE CULTURAL E AGENCIAMENTOS TERRITORIAIS: UMA APRECIAÇÃO TEÓRICO CONCEITUAL
}

\author{
Emerson Costa de Melo ${ }^{1}$
}

\begin{abstract}
Resumo: O presente artigo tem como objetivo discutir o conceito de circularidade cultural empregado pela Geógrafa Aureanice de Mello Corrêa, para analisar as diferentes formas de organização das práticas culturais afrorreligiosas no espaço. Trata-se de um conceito que, em âmbito geográfico, permite identificar a relação entre culturas distintas que se desdobram em territorialidades peculiares, que ora se agenciam, noutras se distanciam num mesmo território. Territorialidades, estas, que serão aqui abordadas a partir da análise das origens das tradições do candomblé presentes nas práticas "católicas" da Irmandade baiana de Nossa Senhora da Boa Morte constituídas, ainda no século XIX, a partir das alianças estabelecidas entre as mulheres - "as negras do partido alto" - que circulavam entre as cidades de Salvador e Cachoeira. Para tanto, o conceito em questão foi analisado sob à luz das categorias conceituais apresentadas pela autora ao longo de sua obra, entre outros textos pertinentes ao debate proposto.
\end{abstract}

Palavras-chave: Circularidade Cultural; Agenciamento Territorial; Candomblé; Irmandade de Nossa Senhora da Boa Morte.

Abstract: The aim of this article is to discuss the concept of cultural circularity used by geographer Aureanice de Mello Corrêa to analyze the different forms of organization of afrorreligious cultural practices in space. It is a concept that, in a geographical area, allows us to identify the relation between distinct cultures that unfold in peculiar territorialities, which sometimes interact, in others they are distant in the same territory. Territorialities, these, which will be discussed here, from the analysis of the origins of the traditions of candomble present in the "Catholic" practices of the Irmandade de Nossa Senhora da Boa Morte, constituted, still in the nineteenth century, from the alliances established among women calls "as negras do partido alto " that circulated between the cities of Salvador and Cachoeira. For this, the concept in question was analyzed in light of the conceptual categories presented by the author throughout her work, among other selected texts.

Keywords: Cultural Circularity; Territorial Agency; Candomblé; Irmandade de Nossa Senhora da Boa Morte.

Resumen: Este artículo tiene como objetivo discutir el concepto de circularidad cultural empleado por la geógrafa Aureanice de Mello Corrêa, a analizar las diferentes formas de organización de las prácticas culturales afroreligiosas en el espacio. Se trata de un concepto que, en ámbito geográfico, permite identificar la relación entre diferentes culturas que se desarrollan en territorialidades peculiares, que en un momento dado se unen, en otros se distancian en el mismo territorio. Territorialidades, estas, que se abordarán aquí a partir del análisis de los orígenes de las tradiciones del candomblé presentes en las prácticas "católicas" de la Irmandade baiana de Nossa Senhora da Boa Morte constituida, aún en el siglo XIX, de

\footnotetext{
${ }^{1}$ Doutor pelo Programa de Pós-Graduação em Geografia da Universidade do Estado do Rio de Janeiro PPGEO/UERJ. E-mail: meloemersonc@ gmail.com. ORCID: https://orcid.org/0000-0002-4395-2517.
} 
las alianzas establecidas entre mujeres: "as mulheres negras do partido alto" - que circulabam entre las ciudades de Salvador y Cachoeira. Para tanto, el concepto en cuestión fue analizado a la luz de las categorías conceptuales presentadas por la autora a lo largo de su trabajo, entre otros textos relevantes para el debate propuesto.

Palabras clave: Circularidad Cultural; Agenciamento Territoriales; Candomblé; Irmandade de Nossa Senhora da Boa Morte.

\section{Introdução}

É preciso, em primeiro lugar, enfatizar que a proposta deste artigo, ainda em caráter introdutório, é promover o debate acerca do conceito de circularidade cultural empregado por Aureanice de Mello Corrêa (2004) em sua tese de doutoramento, intitulada "Irmandade da Boa Morte como manifestação cultural afro-brasileira: de cultura alternativa à inserção global”, para compreender o processo de formação da Irmandade de Nossa Senhora da Morte como uma instituição afrorreligiosa que, embora fundada sob o manto da Igreja Católica, expressa os movimentos de resistência de um grupo particular de mulheres negras de origem africana, responsáveis pela fundação de antigos terreiros de candomblé, ainda nos século XIX, nas cidades de Salvador e de Cachoeira no Recôncavo Baiano.

Cabe mencionar que embora a autora tenha dedicado suas pesquisas à análise dos conflitos decorrentes da disputa de poder e controle da Festa de Nossa Senhora vivenciados pelas Irmãs da Boa Morte frente às imposições da Igreja e, ainda, aos estudos sobre o significado e impacto (político, econômico e cultural) da festa de âmbito local, regional, nacional e global, principalmente ao enaltecer os movimentos de territorialização que indicam a presença de uma circularidade cultural, ou seja, um diálogo entre a prática cultural de origem afro (relegada historicamente ao "lugar de inferior"), com a prática cultural brancohegemônica do catolicismo no Brasil, é que faremos caminho contrário, debatendo a circularidade cultural não só como um diálogo entre o "subalterno e hegemônico" como fora sugerido por Carlo Ginzburg (1987), mas como um movimento de trocas de costumes e tradições de origem negro-africana, que encontram num mesmo espaço de articulação, neste caso o espaço da Igreja, um território de conflitos moldados por relações assimétricas de poder, porém, ainda, um terreno propício para o estabelecimento de práticas rituais tipicamente negras que possibilitam o redesenhar de outras tradições e de novas territorialidades que, a posteriori, se materializariam a partir da consolidação dos terreiros de candomblé .

Enfatiza-se contudo, que não é nossa intenção esmiuçar pormenorizadamente as peculiaridades simbólicas de tal grupo social, ou ainda de rever a análise e objeto da tese em 
questão e, sim, objetivar a contribuição do debate proposto por Corrêa (2004), acerca da circularidade cultural, enquanto um "caminho" e/ou uma "orientação" que possibilite compreender a realidade das práticas culturais afrorreligiosas enquanto processos de resistência em sua forma básica de existência, que ora se agencia, noutras se distancia das estruturas de poder da cultura dominante, uma vez que seu ethos contrapõe-se a essência do projeto colonial branco-hegemônico, materializando-se no espaço por meio de movimentos de territorialização e de territorialidades que se constituem sob os limites de fronteiras porosas, que são e/ou estão em constante atravessamento e ressignificação.

Salienta-se também, que a noção de agenciamento territorial presente na obra da autora e que compartilhamos, corresponde a potência do "ser" negro, neste caso, da mulher negra, em suas mais variadas formas de articulação socioespacial, a quais aproximamos da noção de agenciamento proposto por Asante (2009) quando sugere tal processo como a "capacidade de dispor dos recursos psicológicos e culturais necessários para o avanço da liberdade humana" (p. 94). Neste sentido, os movimentos e ou processos do agency territorial correspondem ao reconhecimento das potências do agente negro em suas mais variadas estratégias para retomada de sua humanidade e liberdade diante o sistema opressor, movimento que se constitui por meio de práticas culturais, políticas e econômicas que se materializam no espaço a partir de territorialidades negras, ou de afro-territorialidades, que delineiam as fronteiras dos territórios da Festa de Nossa Senhora de Boa Morte, na cidade de Cachoeira no Recôncavo Baiano.

É sob tal perspectiva que, brevemente, dividimos o debate proposto em dois momentos, o primeiro destinado a tentativa de esmiuçar o conceito proposto pela autora sem cair em ideias minimalistas de sua acepção e, posteriormente a sua aplicabilidade prática no que tange ao campo de atuação e possibilidade de circulação das Irmãs da Boa Morte pela capital soteropolitana e interior, exercício traçado a partir da revisão de fatos históricos pontuais, os quais, ainda, dividem opiniões. Sobre este quesito, faz-se relevante sinalizar que os agenciamentos - movimentos de organização dos terreiros de candomblé - de tais personagens são discretos e pouco explorados geograficamente, provavelmente devido à ausência de estudos elaborados por geógrafos que se aventuram em tais debates, nem sempre materialmente e espacialmente tão concretos.

\section{Circularidade cultural - o marco teórico-conceitual}


Pautando-se em referenciais da Geografia Cultural, ao investigar a constituição da festa e o sentido de festejar dos participantes da Festa de Nossa Senhora, realizada pela Irmandade da Boa Morte na cidade de Cachoeira, Aureanice de Mello Corrêa (2004) identifica nesta, a presença de territorialidades específicas moldadas a partir do encontro de práticas religiosas distintas, o que lhe permite afirmar que os costumes do candomblé, que se expressam e/ou materializam no espaço através da prática do rito "católico" realizado pela Irmandade.

[...] considerando que o movimento de territorialização, não é inteligível, é invisível, não é dito, é inconsciente, é vivido por cada sujeito, mas se concretiza de fato, como território, através de um processo social, que iniciamos a observação da Irmandade da Boa Morte, como um nexo territorial constituído por suas territorialidades. Territorialidades que passamos a denominar por dois aspectos, de "aparente", significando seus rituais públicos, os atos solenes observados de acordo com o culto católico da dormição de Maria e a Assunção de Nossa Senhora, e, de "subjacente", a territorialidade exercida sob a prática do Candomblé, do culto aos orixás, que estabelece o elo entre as componentes, identificando-as como "da Boa Morte". (CORREAA, 2004, p. 01).

Conforme supracitado, o "nexo territorial", ou seja, o encontro e/ou relação entre a materialidade e a imaterialidade de distintas territorialidades num mesmo espaço, constitui-se a partir de uma lógica cultural "aparente" e "subjacente" que permite às mulheres negras da Irmandade de Nossa Senhora da Boa Morte, manterem vivas às suas tradições a partir de um constante processo de resistência cultural afrorreligioso. Processo, este, que identifica a existência da circularidade cultural, que coloca em constante movimento ideias, costumes e tradições de origens distintas num mesmo processo de articulação que não pode ser entendido apenas pela supressão de uma cultura sobre a outra, ou ainda por aspectos de um sincretismo popular, mas, sim, a partir de um estreito e sensível "diálogo", um jogo de poder que se materializa no território por meio de territorialidades - dinâmicas culturais que articulam no espaço -, porém, que não possuem um limite preciso de cada um de seus campos de influência e controle, pois, neste caso, possuem seus limites constituídos a partir de fronteiras porosas que estão em constante (re)arranjo espacial que variam de acordo com as relações de poder e estratégias de sobrevivência que as envolvem.

Vale ressaltar que tais peculiaridades não devem ser tratadas como quesitos para sua descaracterização, pois a constituição de uma "irmandade de mulheres negras" em meio a hegemonia de uma sociedade branca - masculinizada -, mercantil-escravagista, se configura como processo de resistência em sua essência, que tem como um de seus principais objetivos cumprir com os ritos necessários para garantir a continuidade das tradições das famílias 
negras a elas vinculadas, dentre eles os dois mais importantes: o de assegurar a promoção de casamentos, o que garantirá a continuidade de seu legado por meio da constituição da família, e dos ritos funerários, que garantirão o princípio de renovação da vida - ancestralidade e descendência -, valores civilizatórios comuns às tradições dos povos negro-africanos (MELO, 2014).

Destaca-se que a noção de fronteiras porosas propostas por Corrêa (2004), corresponde à interação e ao atravessamento de elementos materiais e imateriais entre distintas culturas que se fazem precisas para o delinear de outras e novas territorialidades. Trata-se de agenciamentos territoriais, aproximações e distanciamentos geridos a partir de relações de poder e interesse necessários à sobrevivência dos grupos sociais, porém que não devem ser interpretados como forma de submissão de um determinado grupo em relação a opressão de outro, o que denotaria a ausência de potência dos grupos oprimidos e subalternizados em sua (re)ação de contraposição ao sistema hegemônico, prática historicamente exercida pela Irmandade de Nossa Senhora da Boa Morte desde o século XIX.

Portanto, é sob tal crítica que se observa a relevância da aplicabilidade do conceito de circularidade cultural empregado pela autora como uma ferramenta e/ou orientação para o entendimento de tal fenômeno e, ainda, para compreensão das singularidades culturais de ambas as tradições que convivem em estreita articulação num dado território. Articulações, estas, que se agenciam a partir do protagonismo do agente negro, que possibilitam a constituição de outras territorialidades que assegurem a sobrevivência de seus costumes e tradições diante processo de dominação e de imposição cultural.

Faz-se relevante frisar que o conceito empregado por Corrêa (2004), como uma "categoria de análise" para compreender as relações entre culturas distintas no mesmo espaço, constitui-se a partir da noção de "circularidade cultural" elaborada por Ginsburg (1987) no âmbito da História Cultural, o qual sustenta a concepção de cultura como sendo uma "[...] massa de recursos, formas de consciência, crenças e hábitos relacionados a determinado grupo historicamente determinado", dividindo-a em dois níveis: [...] "como cultura popular ou oral e, como cultura erudita ou letrada" (CORRÊA, 2004, p. 20).

Vale recordar que para GINZBURG (1987):

[...] o termo circularidade: entre a cultura das classes dominantes e a das classes subalternas existiu, na Europa pré-industrial, um relacionamento circular feito de influências recíprocas, que se movia de baixo para cima, bem como de cima para baixo [...]. [Trata-se de um], [...] influxo recíproco entre cultura subalterna e cultura hegemônica, particularmente intenso na primeira metade do século XVI. (grifos do autor, p. 13-15). 
Sob a definição apontada, Corrêa (2004) enfatiza que se utiliza do conceito de circularidade proposto pelo autor em tela, por este compreender o "dinamismo da cultura [popular e erudita] como uma produção permanente da sociedade" que está em constante interação. De acordo com a autora, este movimento pode ser identificado "através de dois eixos que compreende como sentido vertical - onde ocorrem influências culturais entre as diferentes classes sociais, num processo de mão dupla - e o sentido horizontal - que viabiliza a troca de experiências e a incorporação destas por culturas distintas" (p. 20).

Ressalta-se que a concepção de cultura, apontada por Corrêa (2004), se materializa a partir de um processo que permite ao ser humano relacionar-se em sociedade e, consequentemente, com o espaço. Para exemplificar tais movimentos a autora invoca as observações de Bonnemaison (2002), no que se refere a análise do espaço vivido e de sua significação simbólica, sugerindo que "este relacionamento apresenta-se como faces de uma mesma realidade, onde a função social e a função simbólica engendram a distinção e a correlação entre o espaço social, o espaço produzido e concebido em termos de organização e produção e o espaço cultural" (p.17) configurando-se a partir de tais relações, territorialidades moldadas a partir de elementos materiais e imateriais que, neste caso, podem ser observadas no encontro e celebração das práticas do candomblé e da Irmandade da Boa Morte.

Acrescenta-se ainda que ao propor o debate inerente a circularidade cultural em âmbito geográfico, Corrêa (2004) identifica nas definições de hierarquias simples e hierarquias complexas propostas por Claval (1999), análise, aliás, que se aproxima à de Ginsburg (1987), a qual caracteriza da seguinte maneira:

[...] as hierarquias simples (o plano vertical) são estabelecidas na escala do ambiente da família ou num ambiente de trabalho, onde os elos verticais são oriundos das necessidades da vida, mas, cimentados através dos laços afetivos e/ou biológicos (elos horizontais) que legitimam a autoridade, sinalizando para uma forma de relações sociais que variam de cultura para cultura, sem, no entanto perder a forca da sua natureza, onde cada um tem, de direito, seu lugar e é limitado, 'a um pequeno grupo num espaço reduzido'. (CLAVAL, 1999, p.21).

Possibilitando a autora caracterizar a cultura, no contexto de sua análise, como:

[...] fonte primordial e, como uma herança cultural, pautadas nas hierarquias, sejam, simples ou complexas, que atuam no processo de formação de uma identidade, constituída por uma busca de reconhecimento coletivo e individual dos seres humanos, criando e atualizando permanentemente através desta dinâmica, a sobrevivência do grupo social e do indivíduo. Ao mesmo tempo, a consideramos como, o principio responsável pelo processo de alteridade, que perpassa de forma coletiva ou individual, todo aquele ou aquilo que subverta o comportamento legado a partir de símbolos e arquétipos criados por determinada cultura hegemônica [...]. (CORRÊA, 2004, p. 22). 
Caracterização pertinente para compreender a constituição da cultura e da identidade como um processo complementar que demostram a emergência de "culturas alternativas" (COSGROVE, 1998), que se manifestam diante a imposição de modelos e de códigos sociais alógenos à sua realidade. Processo de resistência estabelecidos a partir de relações de poder, uma vez que se contrapõem à cultura hegemônica, criando alternativas que possibilitam a delimitação de fronteiras, mesmo que porosas, e ainda, em constante movimento, e a constituição de territorialidades que asseguram a sua identidade constituída no princípio de alteridade, elemento este que se constituí a partir do agenciamento de valores e costumes de origem negro-africana que se entrecruzam na realidade sociohistórica e socioespacial da Irmandade de Nossa Senhora da Boa Morte no espaço da Igreja.

\section{As "negras do partido alto" e o nexo territorial entre o candomblé e a devoção à Nossa Senhora da Boa Morte}

Não resta dúvida sobre o relevante papel das mulheres no processo de constituição do Candomblé da Barroquinha - o İyá Omi Àse Àirá Intilè. Eram elas, as africanas libertas, "as negras do partido alto", que circulavam pela cidade alimentando uma complexa rede pluriétnica que colocavam em movimento as ideias de seu tempo e, ainda, articulando estratégias que facilitavam a sua sobrevivência e permanência de suas tradições e costumes na formação dos terreiros de candomblé do Brasil.

Ao investigar os papeis sociais destas mulheres, que circulavam pelas ruas da cidade de Salvador e de Cachoeira no século XIX, Verger (1999) afirmou que as ilustres damas que fundaram o Candomblé da Barroquinha faziam parte da "Irmandade de Nossa Senhora da Boa Morte”, e que estas dividiam espaço com a Irmandade Senhor Bom Jesus dos Martírios na Igreja de Nossa Senhora da Barroquinha.

Várias mulheres enérgicas e voluntariosas, originárias de kêto, antigas escravas libertas, pertencentes à Irmandade de Nossa Senhora da Boa Morte da Igreja da Barroquinha, teriam tomado a iniciativa de criar um terreiro de candomblé chamado İyá Omi Àse Àirá Intilè, numa casa situada na Ladeira do Berquó, hoje rua Visconde de Itaparica, próxima a Igreja da Barroquinha. (VERGER, 2002, p. 28).

[...] A confraria de N. Sra. da Boa Morte da Igreja da Barroquinha é dirigida pelas mulheres Nagôs [...] São elas que também nesta metade do século XIX, estabelecem e dirigem escondido das autoridades as cerimônias religiosas africanas que serão conhecidas mais tarde sob o nome de candomblé, quando elas poderão celebrá-las livremente. Este grupo de mulheres de aparência muito católica praticante, são ao mesmo tempo, as fiéis guardiãs dos cultos africanos dos orixás nagô-yoruba da atual Nigéria e do Daomé. (VERGER, 1999, p. 221). 
Em oposição a Verger, Silveira (2006) aponta que o terreiro de candomblé instalado na Barroquinha teria surgido sob os auspícios da Irmandade Senhor Bom Jesus dos Martírios, e não da Nossa Senhora da Boa Morte como afirmam os inúmeros estudiosos das religiões afro-brasileiras (p. 445).

O autor é categórico em afirmar que a Irmandade da Boa Morte estava, até meados do século XIX, organizada sob a forma de uma devoção à Nossa Senhora, e que a devoção no contexto colonial correspondia a um culto particular, organizado por amigos e familiares, sem a necessidade de reconhecimento jurídico, diferentemente das irmandades que poderiam surgir de devoções, mas que para se instituírem legalmente deveriam obter o compromisso régio. "Estatuto jurídico definido nas leis portuguesas e no direito canônico, o de instituição das mais importantes, parte integrante da liturgia católica, isto é, o culto público e oficial instituído, portanto elemento básico na estruturação dos poderes na ordem colonial” (p. 446), logo a Irmandade de Nossa Senhora da Boa Morte, seria no período de fundação do terreiro da Barroquinha, isso por volta do final do século XVIII, uma pequena devoção vinculada a Irmandade Senhor Bom Jesus dos Martírios.

Para o autor em tela, tamanho equívoco sobre tal afirmação teria se originado na interpretação realizada por Pierre Verger, sobre o trabalho de João da Silva Campos ([1941] 2001), Procissões tradicionais da Bahia, no qual o autor registraria em suas obras que o terreiro de candomblé da Barroquinha teria sido fundado por mulheres negras da "Irmandade" da Nossa Senhora da Boa Morte e, não, de uma devoção o que promoveria desencontros sobre sua data de constituição. Sobre a questão apontada, Silveira (2006) nos chama atenção para o fato de que Campos (2001) escreveu que os primeiros registros sobre a devoção à Nossa Senhora da Boa Morte na Igreja da Barroquinha datavam de 1851, e que as suas procissões ao “estilo colonial” teriam ocorrido até meados ou, no máximo, até o final dos anos de 1930, quando tiveram suas atividades encerradas.

Entretanto, é importante salientar que a tese de Silveira (2006) não desconsidera ou descaracteriza a participação ou, ainda, o papel e função das mulheres, as "negras do partidoalto", na organização dos terreiros de candomblé. Todavia, o autor sugere que as ilustres senhoras da Boa Morte teriam entrado em cena em outro contexto sociohistórico, relativamente próximo ao da fundação do Ilé Àse İyá Nassò Oká, quando a ilustre İyálórìsá (İyá) Nassò teria transferido o àse (os elementos sagrados) da Barroquinha para a região do Engenho Velho, ainda no primeiro quarto do século XIX. Sendo assim, Silveira considera que foi a Irmandade Senhor Bom Jesus dos Martírios, instalada na Igreja da Barroquinha desde 
1764, que acobertou a formação do primeiro terreiro de candomblé kétu de Salvador, o Candomblé da Barroquinha, e que a devoção a Nossa Senhora da Boa Morte "surgiu posteriormente e deve ter sido um aspecto da ampliação do poder nagô na Bahia e, que as referências a ela nas tradições orais são frequentes porque mulheres importantes no culto aos orixás foram suas dirigentes" (p. 446).

É relevante assinalar que ainda são imprecisos os estudos que atestem efetivamente a data de fundação da devoção a Nossa Senhora da Boa Morte. Muitos pesquisadores traçaram eixos históricos e planos de atuação das lideranças para estabelecer um marco temporal, mas ainda são diversas as conclusões. No mais, a historiografia relata uma divisão entre as devotas da cidade de Salvador e da cidade de Cachoeira, a qual continua a zelar pelos seus costumes e tradições nos dias de hoje. É neste sentido que se faz necessário rever determinados registros históricos para a contextualização da questão apontada, isso, para demonstrar ao leitor o espaço de circulação e articulação de tais mulheres na cidade da Bahia no século XIX, principalmente no processo de constituição dos terreiros de candomblé onde é possível identificar aspectos de circularidades culturais que se constituem espacialmente por meio de nexos territoriais.

João da Silva Campos (2001), foi um dos poucos, se não o único, estudioso do "folclore baiano" que teve acesso aos arquivos da Igreja Nossa Senhora da Barroquinha (antes dos incêndios que quase a consumiriam por completo em 1984), registrando em seus escritos que a Irmandade da Boa Morte apareceria no livro tombo da Igreja da Barroquinha no primeiro ano da segunda metade do século XIX. Nascimento (1988), seguindo às tradições orais dos terreiros de candomblé jeje-nagô de Salvador e Cachoeira, considera o ano de 1820 como o início das atividades da devoção a Nossa Senhora na Barroquinha, período que começaram a se organizar enquanto uma junta de alforria destinada a compra de liberdade de seus membros e, pondera que as "mulheres do partido alto" tenham se organizado sob o modelo de irmandade, somente, a partir dos anos de 1850, concordando aí com os registros apontados por Campos.

Considerando-se a escassez de documentos que atestem uma data precisa para a fundação da devoção a Nossa Senhora da Boa Morte, Aureanice de Mello Corrêa (2004), fundamentada em "nexos culturais e territoriais" que se constituem nos "entres" das fronteiras porosas das tradições nagô-iorubá, especificamente do candomblé, e sua correlação com a Irmandade, traça outro panorama realçando o papel imprescindível das mulheres negras da Boa Morte na formação do terreiro de candomblé do Ilé Às e İyá Nassò Oká. 
Para tanto, a autora apresenta o documento referente ao litígio judicial da Irmandade com a Igreja Católica, Ofício no 002/89, de 04 de agosto de 1989, "no qual a própria diretoria da Irmandade, composta pelas Irmãs da Boa Morte afirmam que a agremiação foi criada há mais de 150 (cento e cinquenta) anos" (p. 174), o que lhe possibilitou, estabelecer como marco temporal, o ano de 1839 para o estabelecimento e/ou fundação da devoção à Nossa Senhora da Boa Morte na cidade de Cachoeira, portanto, período posterior ao de fundação da devoção instalada na Igreja da Barroquinha.

Embora haja divergências entre os autores no que se refere à data de fundação da "Irmandade" da Boa Morte, enquanto um modelo religioso legal reconhecido pela Igreja, possivelmente, esta, desde o primeiro quarto do século XIX, já estaria organizada sob a forma de uma devoção atuando junto a Irmandade Senhor Bom Jesus dos Martírios em frentes de articulação e constituição de terreiros de candomblé.

Neste caso, deve-se recordar que tanto a cidade de Salvador, como a de Cachoeira, estavam conectadas numa rede comum que alimentava o sistema econômico mercantilescravagista, e que as mulheres se deslocavam com maior facilidade do que os homens pelas cidades, tornando-se as principais articuladoras das redes culturais e religiosas que se organizavam sob o modelo de família, reagrupando parentes distantes e cumprindo papéis sociais de extrema relevância para a sobrevivência de sua gente e demais membros inseridos na comunidade, reconstituindo assim, os vínculos destituídos pelo processo de desterritorialização gerado pelo tráfico negreiro, evidências da existência de territorialidades negras que estavam em movimento (MELO, 2014).

Segundo o censo de 1855, eram comuns as relações comerciais e o trânsito de pessoas entre a capital soteropolitana e Recôncavo Baiano, principalmente daqueles que circulavam pela Baixa da Igreja de Nossa Senhora da Barroquinha.

[...] várias pessoas naturais de Cachoeira moravam na Barroquinha; mais determinante ainda é que as redes comerciais e culturais africanas existentes na época cobriam toda a área do Recôncavo, saveiristas, tropeiros e caixeiros viajantes estabeleciam comunicações regulares na região, de modo que algumas conspirações de escravos rebeldes organizadas na capital tiveram suas conexões no interior, e alguns terreiros da capital tinham suas extensões em todo o território da Baía de Todos os Santos. (SILVEIRA, 2006, p. 587).

Diante de tais apontamentos, vale retomar, conforme sinalizado, que as tradições dos terreiros de candomblé sugerem os meados de 1850, como o período de organização ou fundação da devoção a Nossa Senhora da Boa Morte em ambas as cidades, embora os primeiros registros na Barroquinha datem de 1851; e ainda há a hipótese de Corrêa, A. M. (2004) referente ao ano de 1839, para o início das atividades da Irmandade, em Cachoeira. 
Contudo, é possível considerar que a "Irmandade" tenha se articulado enquanto devoção ainda no interior da Igreja da Barroquinha, no espaço de articulação da Irmandade do Senhor Bom Jesus dos Martírios, tendo sido constituída pela ala feminina, composta por africanas oriundas da Costa da Mina e talvez por algumas crioulas delas descendentes ou amadrinhadas, provavelmente com o objetivo de "organizar uma junta de alforria para resgatar sacerdotisas do cativeiro e fundar um candomblé” (SILVEIRA, p. 447).

Ações registradas nas histórias do Zoogodô Bogum Malê Rundó, o conhecido Terreiro do Bogun, considerado o terreiro de candomblé de nação jeje, mais antigo da Bahia, fundado ainda na primeira metade do século XIX, possivelmente em momento análogo ao constituição do Ilé Àse İyá Nassò Oká. Pois, segundo a historiografia afrorreligiosa jeje-nagô as tradições de ambos os terreiros se entrecruzaram em vários momentos da história devido aos vínculos de amizade e proximidades de seus membros, principalmente entre as mulheres que teriam contribuído uma com as outras na organização dos distintos terreiros (PARÉS, 2006). Mulheres estas, integrantes da Irmandade de Nossa Senhora da Boa Morte de Cachoeira.

Portanto, a data de 1839 sugerida por Corrêa (2004), corresponde, neste caso, à época das articulações das negras cachoeiranas, já alforriadas, que segundo os registros históricos teriam dentre os seus principais objetivos a fundação dos terreiros de candomblé (NASCIMENTO, 1988; PARÉS 2006). Diferentemente das mulheres da Barroquinha que já estavam organizadas em torno de um candomblé já consolidado, provavelmente desde os últimos anos do século XVIII (SILVEIRA, 2006). Estas, por sua vez, defenderiam seus interesses, enquanto junta de alforria sob o modelo religioso aparentemente cristão, decorrente da sua articulação com a Irmandade Senhor Bom Jesus dos Martírios que nesta época, estava no auge de sua glória frente às demais Irmandades da cidade de Salvador. Relações estas, que evidenciam o atravessamento de distintas culturas que se materializam no espaço, ora se aproximando, ou se distanciando em nexos territoriais que se arranjam e modulam por e partir de fronteiras porosas em constante interação e atravessamentos.

Contudo, cabe mencionar que as datas indicadas, seja pela tradição oral ou pelos registros documentais, são posteriores à fundação do Candomblé da Barroquinha, pois segundo a historiografia recente, os registros indicam que o İyá Omi Àse Àirá Intilè fora fundado por volta dos últimos anos de 1790, o que geraria uma lacuna temporal de cerca de vinte ou trinta anos entre a data de fundação do terreiro e a organização da devoção a Nossa Senhora da Boa Morte, questão que, aliás, serve de base para a afirmação de Silveira (2006), quando salienta que a "Irmandade" da Boa Morte teria surgido em um momento posterior à organização e/ou fundação do terreiro da Barroquinha. 
Acrescenta-se, ainda, que não há evidências que atestem que as fundadoras do candomblé da Barroquinha, as "rainhas africanas": İyá Adetá, İyá Akàlá e İyá Nassò, principalmente desta que esteve na liderança do Ilé Àse İyá Nassò Oká até o final dos anos de 1860, tenha participado de tal devoção. Nem mesmo se sabe se sua sucessora Marcelina da Silva (İyá $\underline{O} b a$ Tosì) teria se integrado ao grupo. Porém, os registros históricos indicam que Maria Júlia Figueiredo (Ìyá Ómoniké), a terceira İyálórìsá da Ilé Àse İyá Nassò Oká, e Maria Júlia da Conceição Nazaré (İyá Dàda Bàayànì Àjàkú), a fundadora do terreiro de candomblé do Gantois em 1885, e sua sucessora, a İyálórìsá Pulchéria, assim como Eugênia Ana dos Santos (İyá Óba Biyi), a primeira İyálórìsá e fundadora do Ilè Àse Opò Àfònjá em 1920, descendentes diretas das tradições deixadas por İyá Nassò, fizeram parte da devoção a Nossa Senhora da Boa Morte. E que, somente após a morte da última İyálórìsá citada, em 1938, é que a devoção a Nossa Senhora da Boa Morte da Igreja da Barroquinha teria desaparecido da capital soteropolitana, permanecendo ativa até os dias de hoje, na cidade de Cachoeira no Recôncavo Baiano.

Com isso, postula-se que a presença de İyá Adetá, İyá Akàlá e İyá Nassò antecedam a organização da devoção a Nossa Senhora da Boa Morte, estando presentes as duas primeiras na fundação do İyá Omi Àse Àirá Intilè nos fundos da Igreja de Nossa Senhora da Barroquinha, ainda sob uma estrutura de "culto doméstico" e familiar (PARÉS, 2006), enquanto a terceira, em momento posterior, seria a responsável pela transferência do Candomblé da Barroquinha para outra região, estabelecendo um novo modelo de organização socioespacial moldado sob a forma de um território-terreiro de candomblé, moldado partir de nexos territoriais culturais e simbólicas que reorganizam a paisagem sob um modelo e estética que se contrapõe em sua essência ao poder hegemônico.

Acredita-se contudo, que İyá Nassò possa ter circulado junto das irmãs da Boa Morte na capital baiana e, ainda, junto delas, criado estratégias para a fundação de um terreiro de candomblé distante da área central da cidade onde estava instalado o candomblé da Barroquinha. Portanto, não nos seria equivoco sinalizar que o trânsito de tais mulheres e a troca de suas experiências no cotidiano da cidade, tenha colocado ideias em movimento e contribuído para o agenciamento de circularidades culturais que garantiriam a manutenção e sobrevivência de suas tradições que a posteriori se consolidariam em movimentos de territorialização e na própria constituição dos terreiros de candomblé.

Vale recordar, que enquanto eram construídos os alicerces do Ilé Àse İyá Nassò Oká, o Terreiro da Casa Branca sob os cuidados de İyá Nassò, na parte mais alta das terras onde se localizava o terreiro, acerca de 400 metros de distância, eram celebradas as primeiras 
cerimônias religiosas no sítio que mais tarde cederia espaço para a construção do Zoogodô Bogum Malê Rundó, o que coloca em evidência a proximidade e a capacidade de articulação das irmãs da Irmandade da Boa Morte da Barroquinha e de Cachoeira no processo de constituição de ambos os terreiros.

Neste caso, concorda-se com os apontamentos de Nascimento (1988) e Silveira (2006) quando enfatizam que tanto a devoção de Nossa Senhora da Boa Morte, de Salvador, quanto à de Cachoeira surgiram a partir de um mesmo movimento de resistência e necessidade de articulação enquanto juntas de alforria, com vistas à compra de liberdade de outras mulheres escravizadas e, dentre elas, "personalidades" dos cultos africanos (como foi feito com İyá Nassò, conforme indicam as tradições orais afrobaianas), que eram reconhecidas quando desembarcadas na Bahia.

Entretanto, é nítido historicamente que a devoção a Nossa Senhora ligada à Igreja da Barroquinha obteve maior destaque social ainda no início do século XIX, por já possuir um candomblé consolidado e resguardado sob abrigo da Irmandade Senhor Bom Jesus dos Martírios. Uma situação favorável para organizar e elevar sua devoção ao mesmo modelo jurídico das demais irmandades negras e ao ponto de desfilar junto da Irmandade dos Martírios gozando do mesmo status e reconhecimento, sem considerar a suntuosa beleza (SILVA CAMPOS, 2001).

Ao contrário da devoção cachoeirana que, segundo Corrêa, A. M. (2004), manteve, num primeiro momento, sua atenção para os cultos "africanos", possivelmente entre os anos de 1820 a 1850, deixando as tradições católicas em segundo plano utilizando-se delas apenas como estratégias de agenciamento territorial. Ou seja, atuando na promoção de movimentos de luta e resistência em meio as fissuras e permeabilidades do e no espaço da gente branca, o desenhar de circularidades culturais em meio a relações assimétricas de poder.

Ressalta-se que somente após este período, as irmãs da Boa Morte de Cachoeira estabeleceram relações entre ambos universos culturais. Assim sendo, acredita-se que a organização e/ou fundação da "Irmandade" da Nossa Senhora da Boa Morte, na Igreja de Nossa Senhora da Barroquinha, não corresponda ao período de fundação do İyá Omi Àse Àirá Intilẹ̀; mas, sim, ao período de reestruturação ou rearranjo do terreiro, que também corresponde à mudança deste para outra região sob a liderança de İyá Nassò, o que não anula a capacidade do agency de tais mulheres, ou coloca em contradição os aspectos dos nexos territoriais gerados a partir do encontros de distintas matrizes culturais e religiosas, que conforme observado, variam, do início do século XIX ao primeiro quarto do século XX. 
Trata-se, portanto, da localização espaço-temporal de um determinado fenômeno social e da crítica sobre a contradição dos registros grafados pela historiografia afrobaiana.

\section{Considerações finais}

Conforme fora proposto neste exercício reflexivo, nosso interesse repousou sobre a necessidade de compreender a circularidade cultural empregada por Aureanice de Mello Corrêa como uma ferramenta e/ou uma categoria de análise que torna possível compreender as relações subjetivas que envolvem os movimentos, diga-se, culturais e simbólicos que defendem uma identidade comum entre os sujeitos e/ou grupos sociais. A abordagem proposta pela autora, que embora elaborada a partir da análise do conflito local entre a Irmandade da Nossa Senhora da Boa Morte com a Igreja Católica na cidade de Cachoeira, em âmbito geográfico, permite compreender outros fenômenos sociais, em escala global, os quais apresentam em sua realidade espacial as evidências de distintas territorialidades que estão em constante agenciamento.

Deste modo, foi possível identificar que a circularidade cultural aqui analisada corresponde ao movimento de resistência de mulheres negras em tempos de escravização. Ou seja, a capacidade de agenciamento do agente negro em sua articulação territorial. Trata-se de um atravessamento no eixo vertical onde o negro, subjugado a condição de mercadoria - o escravo -, apropria-se de espaços hegemônicos introduzindo ações que assegurem a sobrevivência de seus costumes e tradições, questão evidenciada nos movimentos das irmãs da Irmandade da Boa Morte de Salvador e de Cachoeira, tanto no processo de fundação como de manutenção de terreiros de candomblé.

Neste caso, não seria equivocado afirmar que as tradições católicas resguardadas pela Irmandade Senhor Bom Jesus dos Martírios e, ainda, pela Devoção da Irmandade de Nossa Senhora da Boa Morte possibilitaram a tais agentes - "as mulheres negras do partido alto" circularem por espaços de interesses comuns que contribuíram para a formação e/ou consolidação de terreiros de candomblé na cidade de Salvador, ainda em regime de escravização da gente negra. Portanto, é sob tal crítica que se observa a relevância da aplicabilidade do conceito de circularidade cultural empregado pela autora como uma ferramenta e/ou orientação para o entendimento de tal fenômeno e, ainda, para compreensão das singularidades culturais de ambas as tradições que convivem em estreita articulação num mesmo território. 
Por fim, se a circularidade cultural, no eixo vertical emergir, nesta análise, dos setores subalternizados atingindo as classes mais eruditas rumando horizontalidades nem sempre pacíficas em seu encontro, para Aureanice Corrêa (2004) a circularidade cultural, neste sentido, além de promover "encontros" em verticalidades e horizontalidades, ela possibilita o estabelecimento de práticas de resistência que embora moldadas a partir de aspectos culturais hegemônicos, principalmente na reprodução de padrões, trazem e/ou apresentam por meio de seus agentes subjetividades que envolvem aspectos de uma cultura marginalizada e que mesmo diante a opressão de todo um sistema de mando procura formas de se materializar no espaço. Trata-se do desenhar de territórios por meio de fronteiras porosas que se materializam ou não, a partir do campo de possibilidades das relações que modelam ou regulam o jogo de poder entre seus agentes.

\section{Referências bibliográficas}

ASANTE, Molofi K. Afrocentricidade: notas sobre uma posição disciplinar. In: NASCIMENTO, Elisa L. (Org.). São Paulo: Selo Negro, 2009.

BONNEMAISON, J. Viagem em Torno do Território. In: CORRÊA, Roberto; ROSENDAHL, Zeny. Geografia Cultural: um século (III). Rio de Janeiro: Uerj, 2002.

CAMPOS, João da Silva. Procissões tradicionais da Bahia. $2^{\mathrm{a}}$. Ed. Salvador: Secretaria de Cultura e Turismo; Conselho Estadual de Cultural, 2001.

CORREA, A. M. Irmandade da Boa Morte como manifestação cultural afro-brasileira: de cultura alternativa a inserção global. 2004. 323 f. Tese (Doutorado em Geografia) Universidade Federal do Rio de Janeiro, CCMN/PPGG, Rio de Janeiro, 2004.

COSGROVE, D. A geografia está em toda a parte: cultura e simbolismo nas paisagens humanas. In: CORREAA; ROSENDAHL (coord.). Paisagem, Tempo e Cultura. Rio de Janeiro: EdUerj, 1998.

GINZBURG, Carlo. Introdução. In: $O$ queijo e os vermes: o cotidiano e as idéias de um moleiro perseguido pela Inquisição. São Paulo: Cia. das Letras, 1987.

MELO, Emerson. Entre territórios e terreiros: yorubá, velhos deuses no Novo Mundo. 2014. 234 f. Dissertação (Mestrado em Geografia) - Programa de Pós-Graduação em Geografia, Universidade Federal de Minas Gerais, Belo Horizonte, 2014.

NASCIMENTO, L. A Boa Morte em Cachoeira. Cachoeira: CEPASC, 1988.

PARÉS, Luis Nicolau. A formação do candomblé: história e ritual da nação jeje na Bahia. São Paulo: Unicamp, 2006.

SILVEIRA, Renato da. $O$ Candomblé da Barroquinha: Processo de constituição do primeiro terreiro baiano de keto. Salvador: Edições Mainanga, 2006.

VERGER, Pierre. Notícias da Bahia de 1850. Salvador: Corrupio, 1999.

. Orixás deuses iorubás na África e no Novo Mundo. Trad. Maria Aparecida da

Nóbrega. $6^{\text {a }}$ ed. Salvador: Corrupio, 2002. 